\title{
Impact of International Education on Students' Attitude toward English as Lingua Franca
}

\author{
Chaochang Wang \\ Department of Applied English, Ming Chuan University \\ Taipei, Taiwan \\ caw207@yahoo.com
}

\author{
ChuTai Ho \\ Department of Applied English, Ming Chuan University \\ Taipei, Taiwan \\ cthsnlee@ms16.hinet.net
}

\begin{abstract}
English has long been widely used as a lingua franca (ELF) for intercultural communication and inevitably evolved into various varieties due to its nativisation and localization in different contexts. Its recognition and acceptance, accordingly, are crucial for successful intercultural communication, a goal of international education in higher educational settings. Much research on ELF or world Englishes has been conducted and has findings related to attitudes toward the sociolinguistic reality due to the use of ELF. However, sporadic studies have been conducted on attitudes towards ELF of the students in settings where international education of different forms are provided, and none has been done to compare impacts of these forms on students' ELF attitudes. Therefore, the study introduced in this paper aimed to investigate ELF attitudes of students studying in two types of programs in the same university, one type (the first type) with English as instructional means for all courses and to local students and their international classmates and the other (the second type) with English used only in the 4-year English classes. Questionnaire data were collected and analyzed statistically. Results of the study show significant differences in attitudes of the two groups and have implications for the international education to students in higher educational settings.
\end{abstract}

Keywords- international education; intercultural communication; world Englishes; English as lingua franca $($ ELF); EFL contexts

\section{INTRODUCTION}

English has been recognized as an international language for decades. Its wide-range function pertains to using it not only to native speakers of English but also to non-native speakers of English and for various purposes [1]. Therefore, due to its long-range evolvement integrating cultural and linguistic elements in various regions, English has weathered nativisation and localization and thus has its varieties [1, 2, 3].

Therefore, English language education that is limited to traditional classroom settings and frames of reference is insufficient and hardly adequate $[4,5]$. In such settings, the sociolinguistic reality such as the functions and diversity of the English language is often undervalued.

While English education does not necessarily have to account for different varieties of English by impractically and laboriously teaching them to learners, understanding and experiencing this language's diversity is indispensable for effective communication at all levels (e.g., interpersonal, group, organizational, and intercultural communication). Accordingly, English education at any level may need to sensitize learners to the diversity of English and its speakers from different cultures and reflect this diversity in the curricula to a certain extent. Regretfully, such education has long been ignored in both school contexts and work-site training.

Since internationalization inevitably involves learning of English to bridge the gap between cultures and to recognize differences, elements in English education may have to include the concept of "world Englishes" (Kachru, 1991) or English as lingua franca (Jenkins, 2009). Such education can be of various forms. Among many are international academic programs that bring together both international students and local students. A common feature of such programs is the use of English as the medium of instruction in class and for communication in their campus life. To examine the impact of international education, the purpose of this study is to explore learners' views and attitude toward the linguistic diversity of English after taking classes in such programs

\section{LITERATURE REVIEW}

Reviewed in the following section are the sociolinguistic reality of English and relevant research.

\section{A. English as Lingua Franca and its SociolinguisticReality}

Kachru [1,6] depicted the status and uses of English with a three-concentric diagram. In the inner circle, English is used as a native language and for various purposes. Countries that undoubtedly fall in this circle include USA, UK, Canada, Australia, New Zealand, etc. In the outer circle, English is widely used as an L2 for purposes of intracultural and intercultural communication. While quite a few countries are in this circle such as Singapore, the Philippines, Malaysia, Nigeria, India, Kenya, and so on, numerous countries in the expanding circle are using the language as a foreign language for similar purposes. Not surprisingly to note, there are more nonnative speakers than native speakers. Whose norm should be for English learners? And what model? The discussion on these questions has drawn major issues of concern.

Instead of "world Englishes," Jenkins [2, 7] has opted for a different term, English as lingua franca, to describe the uses of English in the world's multicultural, multilingual contexts. Whether English is described with notions of "world Englishes" or English as lingua franca (ELF), the 
language's sociolinguistic reality and its distinct varieties can be certain. Both have revealed the idea that communication in English does not necessarily have to involve native speakers and often takes place between nonnative speakers of different L1 backgrounds.

To facilitate communication at all levels, the linguistic diversity of the English language cannot be ignored and the legitimate use of varieties depends on "factors such as systematicity, frequency, and communicative effectiveness" [2, p. 202]. Both native speakers and nonnative speakers of English need to make adjustment in communication and display tolerance for varieties other than theirs.

In addition to the recognition of English diversity by both native and nonnative speakers of English, its exposure to English speakers from any of the concentric circles is especially important for mutual understanding. Berns [8] pointed out that each variety is interwoven developmentally with the speaking and discourse conventions in a particular culture and suggested exposure as a means of acquiring such knowledge.

In the classroom, suggested in Jenkins [9] is providing a wide range of varieties so that learners are capable of interpreting aspects of a variety such as pronunciations of speakers different from their own. Encouragingly, research shows intelligibility is easy for most speakers to reach after a brief exposure to a variety of English [10].

Where contact in English is mostly limited to English classes, pedagogical intervention will be instrumental to expose learners to varieties of English [11]. In contexts where contact in English extends to the classroom and beyond, rich exposure to different varieties of English is expected and so are the resultant benefits, in particular, a positive, open attitude toward varieties of English. Whether such an optimal environment facilitates the development of familiarity with English varieties and a positive attitude toward English diversity awaits investigation.

\section{B. Related Research}

Much research has been done on attitudes toward English as lingua franca $[12,13,14,15]$. Most attitudinal studies are about preferred varieties and models for learning. For example, in Seunghee [14], 340 Korean high school students were found to better understand American variety of English and Korean variety than Malaysian English.

Interestingly, the most preferred variety in native speaker models is not necessarily American English. Contrararily, Evans' [16] study, which examined 247 Chinese university students' views of the English varieties, shows American English is not likely to be a model considered "standard" among all. In Ladegaard and Sachdev [17], which examined perceptions of different English varieties, British English (RP) was rated the highest in terms of performance model.

In the world Englishes research related to attitude, some studies have results showing the importance of appreciative attitude toward English varieties [4, 18). Some are related to mutual understanding in a context of English varieties [19, 20]. However, research on the provision of a WE or ELF encouraging environment is sporadic (e.g., [15]).
In view of the literature and relevant research reviewed, scant research studies have been conducted to investigate the impact of international education programs. This study aims to explore students' attitudes toward ELF and its diversities after they are situated in the "internationalization" settings for a period of time. Accordingly, the research questions this study addresses are as follows:

- What attitudes do the juniors in IC have toward English as a lingua franca?

- What attitudes do juniors in non-IC programs have toward English as a lingua franca?

- What is the difference between the attitudes of juniors in IC and in non-IC programs toward English as a lingua franca?

\section{METHODOLOGY}

This study was conducted on the basis of a quantitative research design. Participants included those studying in the programs in the International College (IC) and those in the academic programs that provide the same degree majors with the degree majors provided by IC except that English is not a means for learning and intercultural communication in campus life.

As a result, 361 participants of the study were from the university's IC and non-IC degree programs. 145 junior students were from four programs in IC, and 216, from four none-IC programs. 67 from the IC programs were Taiwanese students, and 78 were international students from Asia, Latin America, Africa, and Europe. Meanwhile, the non-IC student participants were all local Taiwanese. The four IC degree programs are Mass communication, tourism, international business, and applied computing, and the four non-IC programs are of similar programs with the IC's.

Data collection was conducted when the participants were in their $3^{\text {rd }}$ year of study in the university during the first semester. The questionnaire for data collection were pilot-tested and contained 24 likert-scale items and 3 open questions. The likert-scale items investigated attitude toward ELF, English native-speaker model, and communication difficulty.

After the questionnaire responses were collected, data were analyzed using descriptive statistics and inferential statistic procedures (e.g., t-test and ANOVA).

\section{RESULTS}

Results of the study relate to views of IC and non-IC students about ELF and native-speaker model for English learning, as well as difficulty with which they understand English of a variety different from theirs.

Results regarding IC and non-IC students' attitude toward English as lingua franca in terms of English users, English diversity, and ELF acceptance show both groups held a substantially positive attitude toward ELF. They recognized the fact that English users are not limited to native speakers and a result of its use as ELF is its diversity. They also tended to accept this phenomenon. Analysis using descriptive statistics shows the mean scores of all items are above 4.5 out of 6 and the percentage for each is above 80 with most above 90 . Further analysis of the two groups' 
TABLE I. ATTITUDE TOWARD ENGLISH AS LINGUA FRANCA—ELF RECOGNITION AND ACCEPTANCE

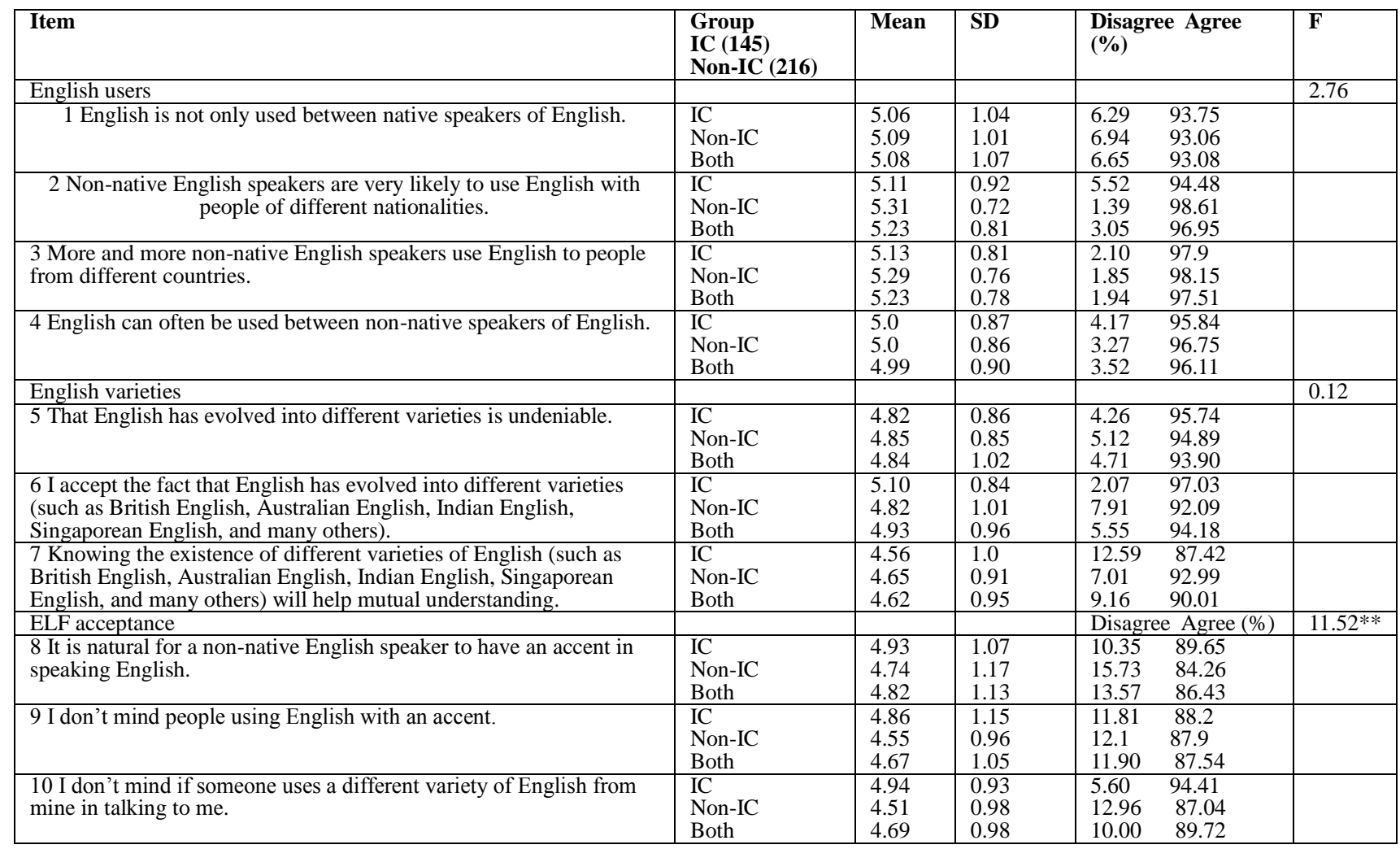

TABLE II. ATTITUDE TOWARD ENGLISH AS LINGUA FRANCA-ENGLISH LEARNING MODELS AND COMMUNICATION DIFFICULTY

\begin{tabular}{|c|c|c|c|c|c|}
\hline Item & $\begin{array}{l}\text { Group } \\
\text { IC (145) } \\
\text { Non-IC (216) }\end{array}$ & Mean & SD & Disagree $\quad$ Agree (\%) & $\mathbf{F}$ \\
\hline Native speaker as model for learning & & & & & $8.05^{* *}$ \\
\hline 11 English is better to be taught by native speakers of English. & $\begin{array}{l}\text { IC } \\
\text { Non-IC } \\
\text { Both }\end{array}$ & $\begin{array}{l}4.60 \\
4.27 \\
4.41\end{array}$ & $\begin{array}{l}1.26 \\
1.24 \\
1.26\end{array}$ & $\begin{array}{ll}19.44 & 80.55 \\
29.77 & 70.24 \\
25.55 & 74.37\end{array}$ & \\
\hline $\begin{array}{l}12 \text { An English native-speaker model should be used for English } \\
\text { learning. }\end{array}$ & $\begin{array}{l}\text { IC } \\
\text { Non-IC } \\
\text { Both }\end{array}$ & $\begin{array}{l}4.39 \\
4.20 \\
4.28\end{array}$ & $\begin{array}{l}1.17 \\
1.11 \\
1.13\end{array}$ & $\begin{array}{l}17.03 \\
23.83 \\
20.81\end{array}$ & \\
\hline $\begin{array}{l}13 \text { Teaching materials should be developed on the basis of the } \\
\text { English-native-speaker model. }\end{array}$ & $\begin{array}{l}\text { IC } \\
\text { Non-IC } \\
\text { Both }\end{array}$ & $\begin{array}{l}4.58 \\
4.17 \\
4.34\end{array}$ & $\begin{array}{l}1.02 \\
1.16 \\
1.12\end{array}$ & $\begin{array}{l}13.38 \\
24.41 \\
19.71\end{array}$ & \\
\hline $\begin{array}{l}19 \text { Native speaker model should be the only model for English } \\
\text { language learners. }\end{array}$ & $\begin{array}{l}\text { IC } \\
\text { Non-IC } \\
\text { Both }\end{array}$ & $\begin{array}{l}3.62 \\
3.36 \\
3.46\end{array}$ & $\begin{array}{l}1.34 \\
1.31 \\
1.33\end{array}$ & $\begin{array}{ll}48.61 & 51.38 \\
58.8 & 41.2 \\
54.72 & 45.28\end{array}$ & \\
\hline Comprehension \& understanding & & & & & $34.91^{* * *}$ \\
\hline $\begin{array}{l}14 \text { I have no problem in understanding others who use a } \\
\text { different variety of English from mine. }\end{array}$ & $\begin{array}{l}\text { IC } \\
\text { Non-IC } \\
\text { Both }\end{array}$ & $\begin{array}{l}4.31 \\
3.80 \\
4.01\end{array}$ & $\begin{array}{l}1.0 \\
0.99 \\
1.02\end{array}$ & $\begin{array}{ll}21.12 & 78.87 \\
36.29 & 63.73 \\
29.92 & 68.87\end{array}$ & \\
\hline $\begin{array}{l}15 \text { I have no problem understanding others who have an accent } \\
\text { in speaking English. }\end{array}$ & $\begin{array}{l}\text { IC } \\
\text { Non-IC } \\
\text { Both }\end{array}$ & $\begin{array}{l}4.31 \\
3.69 \\
3.94\end{array}$ & $\begin{array}{l}1.0 \\
1.06 \\
1.07\end{array}$ & $\begin{array}{ll}19.45 & 80.55 \\
42.13 & 57.87 \\
32.96 & 66.75\end{array}$ & \\
\hline Item & $\begin{array}{l}\text { Group } \\
\text { IC (145) } \\
\text { Non-IC (216) }\end{array}$ & Mean & SD & Disagree Agree (\%) & $\mathbf{F}$ \\
\hline $\begin{array}{l}16 \text { I have difficulty understanding others who use a different } \\
\text { variety from mine. }\end{array}$ & $\begin{array}{l}\text { IC } \\
\text { Non-IC } \\
\text { Both }\end{array}$ & $\begin{array}{l}3.63 \\
3.94 \\
3.82\end{array}$ & $\begin{array}{l}1.16 \\
0.93 \\
1.04\end{array}$ & $\begin{array}{ll}41.01 & 59.0 \\
26.99 & 73.03 \\
31.94 & 66.38\end{array}$ & \\
\hline $\begin{array}{l}17 \text { I have difficulty understanding English by people who have } \\
\text { an accent. }\end{array}$ & $\begin{array}{l}\text { IC } \\
\text { Non-IC } \\
\text { Both }\end{array}$ & $\begin{array}{l}3.51 \\
3.75 \\
3.65\end{array}$ & $\begin{array}{l}1.30 \\
0.90 \\
1.08\end{array}$ & $\begin{array}{l}39.57 \\
36.01 \\
37.42\end{array}$ & \\
\hline
\end{tabular}


attitude toward ELF using ANOVA revealed no significant difference in their recognition of English users and English diversity, with $F$ ratios being $2.76(p>0.05)$ and $0.12(p>0.05)$ respectively. However, there is a statistically significant difference in their acceptance of ELF $(F=11.52, p<0.01)$, with the IC students holding more favorable view than the non-IC students. (See Table 1 and Figure 1.)

As to results about the two groups' attitudes toward native speaker model and the degree of difficulty in communication, both groups tended to favor the native speaker model for English learning and have a moderate level of difficulty in understanding speakers using nonnative speaker English. In addition, comparison results show a statistically significant difference in their attitudes toward native speaker model $(\mathrm{F}=8.05, \mathrm{p}<0.01)$ and the degree of difficulty in communication $(\mathrm{F}=34.91, \mathrm{p}<0.01)$. IC students tend to have a more favorable attitude toward the native speaker model for English learning (Means, 4.26 and 3.97, for 145 IC and 216 non-IC students) and less difficulty in communication in ELF contexts (Means, 3.08 and 3.54, for 145 IC and 216 non-IC students). See Table 2 and Figure 2

\section{CONCLUSION}

This study investigated impact of internationalization at the higher education level using a university in Taiwan as an example. Data for analysis were questionnaire responses of students taking the university's International College (IC) programs and those taking equivalent but non-IC programs. IC's student participants included local Taiwanese and international students. Results of data analysis were summarized and discussed by addressing research questions. Implications of the research findings and limitation of the study were also explored in this section.

\section{A. Discussion}

The first two research questions of the study are related to attitudes the juniors in IC and those non-IC students had toward English as a lingua franca. Averagely speaking, the IC and non-IC participants of the study were positive about the status of English as a lingua franca in terms of their knowledge of English users and English diversity as well as their acceptance of such diversity.

The overall favorable attitude toward English status and diversity may be a result of rich exposure of and accesses to ELF in the contexts where the participants were located. A most likely reason for the approving attitude toward ELF may be the levels of internationalization in the university where this study was conducted. The International College (IC) of the university provides bachelor-degree programs to both international and local students. IC's international students with different nationalities (n), such as countries in Latin America, Africa, and Europe, get to interact with not only Taiwanese students but most likely with other international IC students, and IC's Taiwanese students attend the same classes with their international classmates. The environment itself provides rich ELF exposure and contexts for adjustment and acceptance. For non-IC Taiwanese students who were of the same majors as those IC students, though they were taking non-IC programs, they may have been sensitized to the different English users and English diversity with the campus internationalization that is partially attributed to the international students in the university. In addition, they are all required to take four-year English, which may also contribute to their attitude toward ELF. The internationalization on campus may have created abundant opportunities for ELF exposure and interaction in the classroom and/or outside the classroom and very likely helped shape supportive attitude toward ELF. The results echo findings in Morrison \& White [18], in which components that helped shape students' favorable attitude in the World English Program in Chukyo were found to be related to the bounty opportunities for students to be familiar with different English varieties.

As to both groups' preference for native speaker model, previous research has yielded similar findings. In $\mathrm{Hu}[12$, 21], most of the 1251 university students were found to favor American English. In Seunghee [14], 340 Korean high school students preferred reportedly American English to Malaysian English and Korean variety. Furthermore, Munro [13] studied international graduate students' views toward English and found their positive attitude toward American English. There have also been quite a few studies revealing student participants' favorable attitudes toward other native speaker models, such as British English [16, 17]. The findings of substantial relevant research studies also show nonnative English speakers' general preference for native speaker models, as it was found in Jenkins's [22].

The $3^{\text {rd }}$ research question relates to a comparison of the IC students and non-IC students in terms of their attitude toward ELF and English learning models. While there was no significant difference in both IC and non-IC students' knowledge of English users and English diversity, there was a significant difference in their acceptance of English diversity, their view about English learning models, and their difficulty in understanding English that is different to them. IC students tend to accept English varieties more than non-IC students. They were more prone to agree that it is natural for a non-native English speaker to have an accent in speaking English and they don't mind people using English with an accent or a different variety. It seems that the context where the $3^{\text {rd- }}$ year IC students were situated did make a difference in nurturing students' attitude about ELF and its diversity. As to their views about English learning model, it is interesting to note that IC's students were more positive about native-speaker models for English learning. This may be due to, aside from the abovementioned reasons, their experience of interaction with their peers from different countries and, hence, more efforts for explanation and interpretation as well as constant adjustment of their use of English. Another difference between the two groups of students is their perceived difficulty in understanding others using different English varieties. IC's students tended to have less difficulty than non-IC students. Again IC's education may have contributed to the result. IC students use English every day in class and after class to their professors and their classmates of varied nationalities. At their third year in IC, they may have been more familiar with English diversity than the non-IC juniors. Previous research $[15,19]$ 
have indicated the importance of exposure of English diversity for English learners. Yoshikawa [15] studied the impact of the World Englishes (WE) Program in Chukyo University. The questionnaire investigation shows the WE students had a more positive attitude toward the sociolinguistic phenomena of English use than the English majors and the non-majors. Results also showed the longer the participants studied in the WE program the more favorable their attitude tended to be, indicating the power of the WE program.

\section{B. Implications and Suggestions for Future Research}

Results of this study have implications for international education. The high-scale of internationalization shaped with the establishment of an international college that provides degree-programs to not only international students but also local students has provided rich exposure to English as lingua franca (ELF). Such internationalization on campus in this study may have helped promote recognition and acceptance of ELF and, hence, may serve as a model to be used in higher education in Taiwan and in other EFL contexts. The form of internationalization in this study may have contributed to the positive attitude of most participants, both IC students and non-IC students, toward ELF in terms of its recognition, diversity, and acceptance and made a difference between those in IC and those in non-IC similar degree-programs in shaping their attitude toward ELF.

The results of this study also have a pedagogical implication. For the non-IC students, the existence of IC and international students on campus helps increase their exposure to ELF and very likely nurture their positive attitude toward ELF. However, they held less favorable attitude toward ELF diversity and its acceptance than the IC students. This implies a need for pedagogical intervention for the non-IC students and university students in similar contexts. Intervention in their English class can further strengthen their sense of ELF, which will contribute partially but significantly to their intercultural communication success.

Nevertheless, this study has its limitations. It included only data from junior students in IC and non-IC programs in this university. However, data from students of other years may yield more information about the impact of the unique form of internationalization in this university. In addition, views of university staff, teachers and, in particular, English teachers were not taken into account in this study. Their views may help an understanding of the way the internationalization on campus and students' ELF attitude are shaped.

For future research on ELF in similar contexts, questionnaire responses are suggested to include those from freshmen, sophomores and seniors. This makes comparison between groups of different years possible and longitudinal studies easier. Future studies are also highly suggested to include views of teachers and university staff members, whose attitude toward ELF may affect substantially students' attitude and, thereafter, their intercultural communication competence in using English pragmatically.

\section{REFERENCES}

[1] Kachru, B. (1991). World Englishes And Applied Linguistics [ebook]. Available from: ERIC, Ipswich, MA.

[2] Jenkins, J. (2009). English as a lingua franca: interpretations and attitudes. World Englishes, 28(2), 200-207.

[3] Kachru, Y, \& Smith, L. E. (2009). The Karamic cycle of world Englishes: Some futuristic constructs. World Englishes, 28(1), 1-14.

[4] Brown. H.D. (2007). Principles of language learning and teaching. White Plains, NY: Longman.

[5] Savignon, S.J. (1997). Communicative competence: Theory and classroom practice $\left(2^{\text {nd }}\right.$ ed). New York: McGraw-Hill.

[6] Kachru, B. (1996) English as lingua franca. In Hans Goebl, Peter H. Nelde, Zdenek Stary, and Wolfgang WÖlck (eds.), Contact Linguistics: An International Handbook of Contemporary Research (pp. 903-6). Berlin: de Gruyter.

[7] Jenkins, J. (2006). Current perspectives on teachingWorld English and English as a Lingua Franca. TESOL Journal, 40, 157-81.

[8] Berns, M. (2008). World Englishes, English as a lingua franca, and intelligibility. World Englishes, 27(3/4), 327-334.

[9] Jenkins, J. (2002) A sociolinguistically based, empirically researched pronunciation syllabus for English as an international language. Applied Linguistics 23, 83-103.

[10] Smith, L. E., and Rafiqzad, Khalilulla (1979) English for crosscultural communication: the question of intelligibility. TESOL Quarterly 13, 371-80. Repr. 1983 in Larry E. Smith (ed.), Readings in English as an International Language (pp. 13-20). Oxford: Pergamon.

[11] Matsuda, A. (2003). The ownership of English in Japanese secondary schools. World Englishes 22 (4): 483-96.

[12] Hu, X. (2004) Why China English should stand alongside British, American and the other world Englishes. English Today 20, 26-33.

[13] Munro, V. R. (1996). International Graduate Students and the Spread of English. World Englishes, 15(3), 337-45.

[14] Seunghee O. (2011). Effects of Three English Accents on Korean High School Students' Listening Comprehension and Attitude. English Teaching [serial online]. Spring2011 2011;66(1):39-63. Available from: Education Research Complete, Ipswich, MA Accessed December 26, 2011.

[15] Yoshikawa, H. (2005). Recognition of world Englishes: changes in Chukyo University students' attitudes. World Englishes, 24(3), 351360.

[16] Evans, B. E. (2010). Chinese Perceptions of Inner Circle Varieties of English. World Englishes, 29(2), 270-280.

[17] Ladegaard, H. J. \& Sachdev, I. (2006). I like the Americans . . . but I certainly don't aim for an American accent: language attitudes, vitality and foreign language learning in Denmark. Journal of Multilingual and Multicultural Development 27, 91-108.

[18] Morrison, R., \& White, M. (2005). Nurturing global listeners: increasing familiarity and appreciation for world Englishes. World Englishes, 24(3), 361-370.

[19] Kaur, J. (2010). Achieving mutual understanding in world Englishes. World Englishes, 29(2), 192-208.

[20] Smith, L. E. (1992) Spread of English and issues of intelligibility. In Braj B. Kachru (ed.), The Other Tongue, $2^{\text {nd }}$ edn (pp. 75-90). Urbana: University of Illinois Press.

[21] Hu, X. (2005) China English, at home and in the world. English Today 21, 27-38.

[22] Jenkins, J. (2007). English as a Lingua Franca: Attitude and Identity. Oxford: Oxford University Press. 